Acta Theriologica 38, (4): 427 - 434, 1993.

PL ISSN $0001-7051$

\title{
Home range and activity patterns of red fox Vulpes vulpes breeding females
}

\author{
Alejandro TRAVAINI, Juán J. ALDAMA*, Rafael LAFFITTE \\ and Miguel DELIBES
}

\begin{abstract}
Travaini A, Aldama J. J., Laffitte R. and Delibes M. 1993. Home range and activity patterns of red fox Vulpes vulpes breeding females. Acta theriol. 38: $427-434$.

Home range size and activity pattern were evaluated by radiotracking for seven red fox Vulpes vulpes (Linnaeus, 1758) breeding females, in the Doñana Biological Reserve, SW Spain. Mean home range size was 218 ha $(\mathrm{SD}=76, n=7)$. A home range for one of the seven females was 1129 ha for one nearly complete year and only 253 ha for the same female during the breeding season. We suggest that this size reduction could be a result of energetical and behavioral shifts due to the breeding condition. Activity was slightly increased during nights with long resting periods during light hours. Total mean travelling distances was $6686 \mathrm{~m}$ in 24-hour cycles. Daytime and nighttime mean distance covered were 2101 and $4585 \mathrm{~m}$, respectively.

Consejo Superior de Investigaciones Científicas, Estación Biológica de Doñana, Apartado 1056, 41080 Sevilla, Spain

Key words: Vulpes vulpes, home range, activity pattern, breeding season
\end{abstract}

\section{Introduction}

In the red fox Vulpes vulpes (Linnaeus, 1758) breeding season occurs during winter (Lloyd and Englund 1973). In Spain, females come into oestrus usually in December, and after a gestation period of about 52 days (Bros 1987) between two and six cubs are born. In the Doñana National Park births are concentrated mainly between the end of February and the end of March, and the cubs start going outside the den during May.

Gestation, lactation and rearing up the cubs request a great amount of energy. In red foxes, in spite of some food and care provided occasionally by the male and/or some helpers (Macdonald 1980, 1981, Schantz 1984), the greater parental investment during reproduction is made up by the female. As a result of the female breeding activity, some shifts in her habits could be promoted, due to the greater spatial and temporal dependence of the den, the increased energetic demands, etc. Such changes could be reflected in her home range size and activity pattern.

*Present address: Instituto Nacional para la Conservación de la Naturaleza, Parque Nacional de Doñana, Matalascañs 21760, Huelva, Spain 
Home range size reduction during pregnancy was observed by Rau (1987) for one female red fox radiotracked during two consecutive breeding seasons. A similar reduction in home range size related to denning was detected for coyotes (Person and Hirth 1991, Holzman et al. 1992). Shifts in activity patterns were also detected by Rau (1987), who observed that daily movements of one red fox breeding female were reduced during her breeding season, and by Phillips and Catling (1991), who observed that breeding females shifts from nocturnal to mainly diurnal activity during denning.

This paper documents the home range size and activity patterns of six red fox breeding females during one breeding season. We also present a reduction of the home range size during breeding in a red fox female radiotracked for nearly one whole year.

\section{Study area and methods}

The study was conducted in the Doñana Biological Reserve, a protected area of $70 \mathrm{~km}^{2}$ inside the Doñana National Park $\left(500 \mathrm{~km}^{2}\right) \mathrm{SW}$ Spain. The whole place is a flat zone at sea level on the right bank of the Guadalquivir river mouth (approximately $37^{\circ} 00^{\prime} \mathrm{N}, 06^{\circ} 30^{\prime} \mathrm{W}$ ).

Three environmental units can be recognized in Doñana area: the marshland that remains flooded from October/November to May/June, the mediterranean shrub, and the sand dunes. Foxes can be found in the three units, however all the individuals marked for this study were captured in the shrubland. Two mayor types of habitats can be found in this unit: (1) a 40 year old dense and homogeneous pine plantation of Pinus pinea and (2) the natural shrubland formed mainly by Erica sp. and Hallimium halimifolium with scattered cork-oak Quercus suber trees. More information can be found in Allier et al. (1974) and Rogers and Myers (1980).

Field data came from radiotracking of one female from July 1985 to April 1986 and six females in the 1990 breeding season (Table 1). We consider as breeding season the time from the onset of oestrus to an arbitrary state of development of the cubs (e.g. when they started excursions out of the den). For our six females from 1990, the radiotracking began when they were finishing pregnancy or begining lactating, and it ended when cubs start excursions out of the den, during May.

Steel leg-hold traps (Victor number 2 Coil Spring specially modified to reduce foot injuries) were used to capture the animals. They were immobilized with an intramuscular injection of a combination of ketamine hydrochloride and xylazine hydrochloride (Travaini et al. 1992). Breeding condition of the seven females was assessed by detecting conspicuous foetuses or clear signs of being lactating. Each

Table 1. Radiotracking period, intensive 24-h periods, and number of radio-locations of seven vixens in the Doñana Biological Reserve.

\begin{tabular}{llcr}
\hline Fox number & \multicolumn{1}{c}{ Radiotracking period } & Trackind 24 h & Number of locations \\
\hline VF03 & July 1985 - April 1986 & 0 & 215 \\
VF05 & April 1990 - May 1990 & 0 & 33 \\
VF06 & March 1990 - May 1990 & 2 & 120 \\
VF07 & April 1990 - May 1990 & 1 & 50 \\
VF08 & February 1990 - May 1990 & 2 & 159 \\
VF09 & February 1990 -May 1990 & 3 & 143 \\
VF10 & March 1990 - April 1990 & 1 & 58 \\
\hline
\end{tabular}


fox was equipped with a transmitter incorporating a mercury switch (Telemetry Systems Inc. and Wildlife Materials Inc.), indicating movement by changes in pulse rate. A directional antena allowed determination of both location and activity .

Each animal was localized from one to three times at all times of day and night. Intensive 24-h radiotracking periods with 1 -h intervals were also made (Table 1). Following Servin et al. (1991) we considered nocturnal period from 18:01 to $06: 00 \mathrm{~h}$, and diurnal period from 06:01 to 18:00 $\mathrm{h}$. Localizations were made using the triangulation method (Mech 1983). We estimated accuracy to be about $100 \mathrm{~m}$, with a system error of $5^{\circ}$ and mean observer-animal distance usually less than $1 \mathrm{~km}$. Information recorded at each fix were time, location and the status of the animal (entered as active or stationary). Home range size was calculated by the convex polygon method (Mohr 1947).

Daily resting time and daily travelled distance were estimated from 24-h monitoring periods. Inactive fixes were considered when average distance between one hourly localization and the next was lesser or equal to $100 \mathrm{~m}$ (we considered $100 \mathrm{~m}$ as the error of the triangulation method employed to localize the animal). Resting was assumed when locomotor activity between consecutive fixes was not detected and the sensor did not detect activity. To estimate daily travelled distance we added the straight-line distances between consecutive locations of each 24-h monitoring period. Independent and paired comparisons were made using the Student $t$-test, the $p<0.05$ calculation was required for the statistical significance (Zar 1984: 150 - 152).

\section{Results}

For all the seven females we had enough fixes to draw up a realistic home range (Ables 1969) during the breeding season and for one complete year for VF03 female (Fig. 1). Mean home range for the 7 breeding females was 218 ha $(S D=76)$. All known dens were sited closed to the center of the home range (Fig. 1).

In spite of having only one case, it is important to notice the existence of a seasonal reduction in the home range size during the breeding season. The female

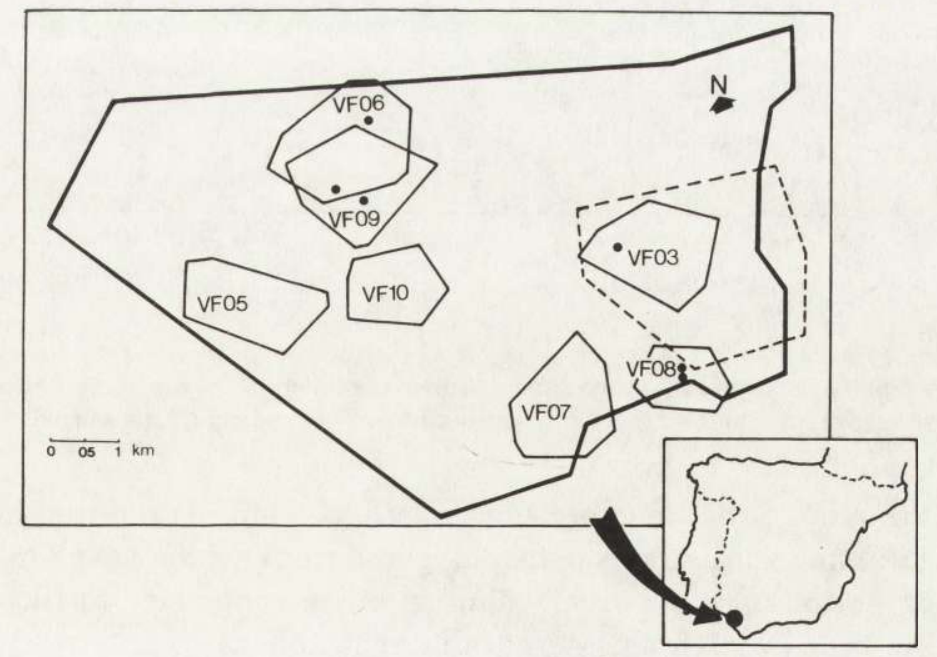

Fig. 1. Home range of seven breeding females at the Doñana Biological Reserve (thick continuous line). ( - ) delimits breeding season home ranges, ( --. ) delimits home range for one complete year for VF03 female. Dots indicate den locations; two dens for VF09 and VF08 females are shown. 
Table 2. Home range size (ha) of seven breeding females calculated using the minimum convex polygon method, average distance $(\mathrm{m})$ travelled in a complete $24-\mathrm{h}$ period $(\mathrm{AD})$ and its range, and mean number of inactivity hours within a 24-h period (IH) with its range.

\begin{tabular}{lcrcrc}
\hline Fox number & $\begin{array}{c}\text { Minimum convex } \\
\text { polygon }\end{array}$ & $\mathrm{AD}$ & Range & IH & Range \\
\hline VF03 & 253 & & & & \\
VF05 & 230 & & & & \\
VF06 & 314 & 10,130 & $8,817-11,430$ & 4.5 & $2-7$ \\
VF07 & 237 & 9,655 & & 6.0 & \\
VF08 & 278 & 5,120 & $2,425-7,261$ & 9.5 & $5-18$ \\
VF09 & 276 & 5,175 & $3,239-7,111$ & 11.0 & $5-17$ \\
VF10 & 171 & 5,307 & & 9.0 & \\
Mean & 218 & 6,686 & $2,425-11,430$ & 8.0 & $2-18$ \\
\hline
\end{tabular}

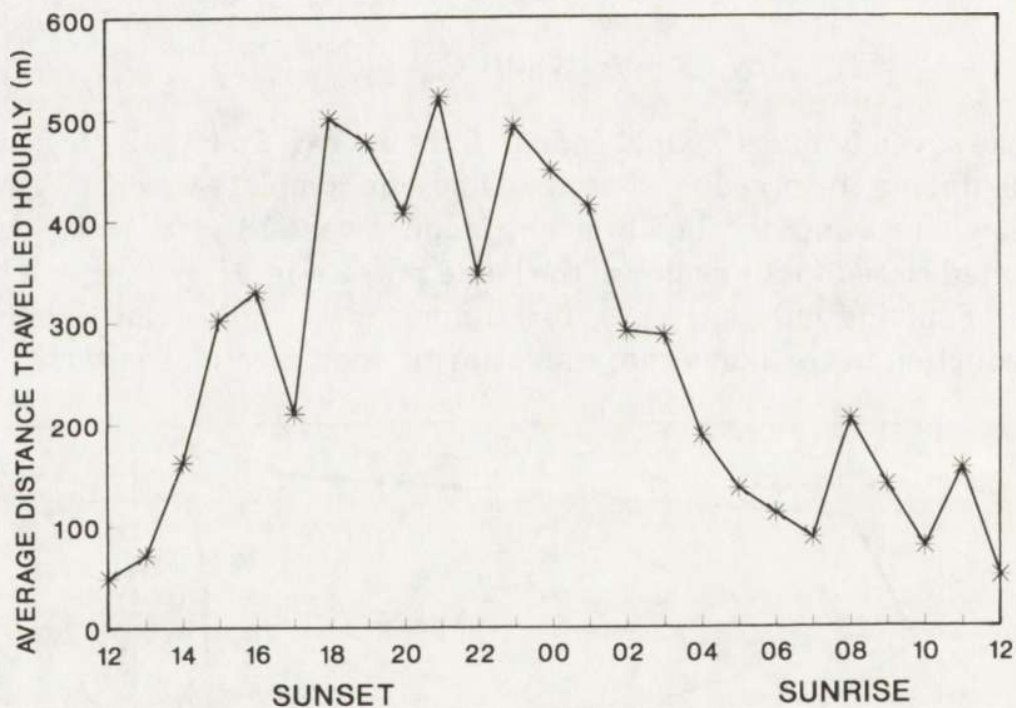

Fig. 2. Activity pattern (expresed as average distance travelled hourly in meters) during the breeding period for six breeding females estimated from intensive 24-h radiotracking periods with 1-h intervals.

radiotracked outside the breeding season (VF03; Table 1) reduced her home range size from 1129 ha (minimum convex polygon for one whole year), to 253 ha during the denning period (Fig. 1), a very similar home range size to those obtained for the other six breeding females 4 years later (Table 2).

Activity during the breeding period involved in this study exhibits a slight tendency to a nocturnal pattern, including sunset, sunrise and night hours (Fig. 2). Females reduce their movements during light hours, spending long resting 


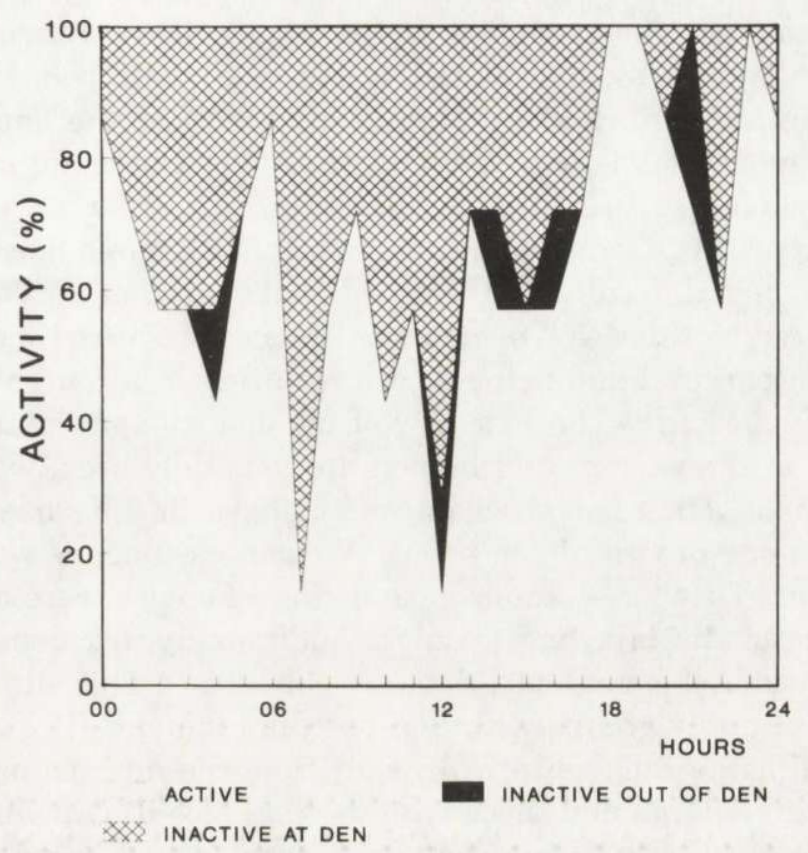

Fig. 3. Percent of active and inactive time estimated from intensive 24-h radiotracking periods. Two possible inactive situations were considered: inactive at the den and inactive at any other place.

periods at the den with the cubs (Fig. 3). Total mean travelling distances for red fox breeding females in Doñana was $6686 \mathrm{~m}$ in 24-h cycles $(n=9)$. Daytime mean distance covered was $2101 \mathrm{~m}$, while in the night periods foxes moved $4585 \mathrm{~m}$. So, nocturnal movements were larger than diurnal ones $(t=3.6, \mathrm{df}=16, p<0.01)$.

Four of the seven females occupied to the pine forest habitat (VF05, VF06, VF08, and VF10) and the other three to the scrubland habitat. Females were assigned to a particular habitat type when the $80 \%$ or more of their home range was inside that habitat. In spite of an expected difference favouring bigger home ranges in the poorer and less diverse habitats (Ables 1969, Maurel 1980) we have not found statistical differences between home range sizes in the pine forest and the scrubland $(t=0.19, \mathrm{df}=5, p=0.86$ ). Moreover, mean home range size from the scrubland was slightly bigger than that from the pine forest.

\section{Discussion}

During the breeding season habitat requirements may be quite different from those during the rest of the year (Tester and Siniff 1974). The home range concept is closely tied to energy requirements of each species at any moment of its life (McNab 1963, Goszczyński 1986). So its size and shape will vary according to this 
important parameter. The reduction of the female home range size during the breeding season is undoubtedly related, energetically and behaviorally, with gestation, lactating and cub rearing. Taking into account the energetical demand increase, that the red fox female must confront when breeding, one could expect a proportional increase in her home range size in order to obtain extra food resources. Against this, favouring a reduction in the female home range size, are those activities related to cubs care. This inevitably greater dependence to the den could be enhanced by their well documented social structure (Macdonald 1980) in the way of male parental and helpers care resulting in a concentrated activity of the breeding female in the close vicinity of the den. In spite of not have concrete proofs in favor of the existence of helpers in our study area, we can notice that on two occasions a young barren vixen was trapped in the same trap that was a breeding female one or two nights before. We can assume, as we were out of the dispersing period (October - January) that these females were occupying part of the home range of the breeding females. Additionally, fox density in the study area can be considered as high ( $1.7 \mathrm{fox} / \mathrm{km}^{2}$, Rau 1987). This situation could favor the formation of family groups with non-breeding females (Brown 1974, Schantz 1984). The final home range size will result from the interactions between those factors tending to enlarge and those tending to reduce it. Our findings in Doñana suggest that a reduction in home range size result when breeding. A similar reduction pattern was also described for coyotes Canis latrans (Hibler 1976, Laundré 1979). On the other hand, Phillips and Catling (1991) found no home range size differences between pre-denning and denning periods for one male and one female red fox in Australia.

Nevertheless, because of the great deal of variation reported, caution must be taken when interpreting home range size in red foxes. Phillips and Catling (1991) described home ranges of 500 ha and 530 ha for one male and one female in Australia. Voigt and Macdonald (1984) reported home ranges between 10 and 250 ha for Oxfordshire (England) and 500 to 2000 ha for Ontario (Canada). Many possible causes have been identified as determinants of home size in red foxes. Food availability (Ables 1969, Maurel 1980, Voigt and Macdonald 1984) and fox density (Niewold 1980) were among those best recognised. As a remarkable prove of red fox home range size varation we can mention the results obtained by Servin et al. (1991) working at the Doñana Biological Reserve. In the same area as ours, just several years before, they found a mean home range size for two females and four males (radiotracked between 73 and 159 days) of 116 ha, just the half of our results. However, Servin et al. (1991) did not clarify if this home range mean size corresponds to one month or for the whole radiotracking period. Blanco (1986) found that in central Spain the home range of one male of red fox was 113 ha.

Activity patterns of red fox breeding females in Doñana did not show any clear cut preference to nocturnal activity like that described by some other authors (Phillips and Catling 1991), although, in spite of being primarily nocturnal, they showed some daily activity similar to that described by Storm (1965) and Tester 
(1987). Nocturnal activity of females as described in this study coincides with that found by Servin et al. (1991), but opposes to that described by Phillips and Catling (1991) wich found that during pre-denning the activity of the female was mostly nocturnal while during denning activity was reduced and shifts to a most diurnal pattern. Its general activity pattern shows a 24 -h activity waveform with relatively long periods of rest during the day followed by relatively long periods of movements at night. Mean distances travelled by the females during day and night were similar (specially for the night period) to those described by Servin et al. (1991) for red fox females (1350 and $4580 \mathrm{~m}$ during day and night, respectively) in spite of their longer study period (from February to June 1985). They have not made any mention on the breeding condition of the females.

In addition to those behavioral and energetic shifts due to reproductive activities affecting home range size and activity patterns are all those just mentioned. This high variability shown by red foxes not only in home range size but also in activity patterns was stressed by Voigt and Macdonald (1984) and clearly shows the limited value of extrapolations for this species.

Acknowledgements: We thank the staff of the Doñana Biological Reserve. J. A. Donazar and H. Okarma and two anonimous referees improved previous drafts. Funds were provided by the Instituto para la Conservación de la Naturaleza (ICONA) and Dirección General de Ciencia y Tecnología; Project PB90-1018.

\section{References}

Ables E. D. 1969. Home range studies of red foxes (Vulpes vulpes). J. Mammal. 50: 108-120.

Allier C. F., Gonzales Bernaldez F. and Ramirez Díaz L. 1974. Mapa Ecológico de la Reserva Biológica de Doñana. CSIC. Estación Biológica de Doñana.

Blanco J. C. 1986. On the diet, size and use of home range and activity patterns of a red fox in central Spain. Acta theriol. 31: $547-556$.

Bros J. R. 1987. La reproduction du renard roux. These pour le doctorat veterinaire diplome d'etat. Université Paul-Sabatier de Toulouse, Toulouse: $1-126$.

Brown J. L. 1974. Alternate routes to sociality in jays - with a theory for the evolution of altruism and communal breeding. Am. Zool. 14: $63-80$.

Goszczyński J. 1986. Locomotor activity of terrestrial predators and its consequences. Acta theriol. 31: $79-95$.

Hibler S. J. 1976. Coyote movement patterns in Curlew Valley with emphasis on home range characteristics. M.S. thesis, Utah State Univ., Logan: $1-112$.

Holzman S., Conroy M. J. and Pickering J. 1992. Home range, movements, and habitat use of coyotes in Southcentral Georgia. J. Wildl. Manage. 56: 139 - 146.

Laundré J. W. 1979. A behavioral study of home range utilization by coyotes on the INEL site in southeastern Idaho. Ph. D. thesis, Idaho State Univ., Pocatello: $1-70$.

Lloyd H. G. and Englund J. 1973. The reproductive cycle of the red fox in Europe. J. Reprod. Fert. Suppl. 19: $119-130$.

Macdonald D. W. 1980. Social factors affecting reproduction amongst red foxes. [In: The red fox. E. Zimmen, ed]. Biogeographica 18: 123 - 175 .

Macdonald D. W. 1981. Resource dispersion and the social organization of the red fox (Vulpes vulpes). [In: Proceedings of the Worlwide Furbearer Conference. J. Chapman and D. Pursely, eds]. Worldwide Furbearer Conference Inc., Maryland: 918 - 949. 
Maurel D. 1980. Home range and activity rhythm of adult male foxes during the breeding season. [In: A handbook on biotelemetry and radio tracking. C. J. Amlaner and D. W. Macdonald, eds]. Pergamon Press, Oxford: 697 - 702 .

McNab B. E. 1963. Bioenergetics and the determination of home range size. Am. Nat. $97: 133-140$.

Mech L. D. 1983. Handbook of animal radio-tracking. University of Minnesota Press, Minneapolis: $1-107$.

Mohr C. O. 1947. Table of equivalent populations of North American small mammals. Amer. Midl. Natur. 37: $223-249$.

Niewold F. J. J. 1980. Aspects of the social structure of red fox populations: a summary. [In: The red fox. E. Zimmen, ed]. Biogeographica 18: 185 - 193.

Person D. K. and Hirth D. H. 1991. Home range and habitat use of coyotes in a farm region of Vermont. J. Wildl. Manage. 55: $433-441$.

Phillips M. and Catling P. C. 1991. Home range and activity patterns of red foxes in Nadgee Nature Reserve. Wildl. Res. 18: $677-686$.

Rau J. R. 1987. Ecología del zorro, Vulpes vulpes (L.), en la Reserva Biológica de Doñana, S. O. de España. Tesis Doctoral. Facultad de Ciencias Biológicas. Universidad de Sevilla: 1 - 265.

Rogers P. M. and Myers Y. 1980. Animal distributions, landscape classification and wildlife management, Coto Doñana, Spain. J. Appl. Ecol. 17: 545 - 565.

Schantz T. von. 1984. 'Non-Breeders' in the red fox Vulpes vulpes: a case of resource surplus. Oikos 42 : $59-65$.

Servin J., Rau J. R. and Delibes M. 1991. Activity pattern of the red fox (Vulpes vulpes) in Doñana, SW Spain. Acta theriol. 36: $369-373$.

Storm G. L. 1965. Movements and activities of foxes as determined by radio-tracking. J. Wildl. Manage. 29: 1 - 13 .

Tester J. R. 1987. Changes in daily activity rhythms of some free-ranging animals in Minnesota. Can. Field-Natur. 101: $13-21$.

Tester J. R. and Siniff D. B. 1974. Relevance of home range concepts to game biology. [In: 11th International Congress of Game Biology]. Stockholm, Sweden: 287 - 296.

Travaini A., Ferreras P., Delibes M. and Aldama J. J. 1992. Xylazine hydrochloride-ketamine hydrochloride immobilization of free-living red foxes (Vulpes vulpes) in Spain. J. Wildl. Dis. 28: 507 - 509.

Voigt D. R. and Macdonald D. W. 1984. Variation in the spatial and social behaviour of the red fox, Vulpes vulpes. Acta zool. Fenn. 171: $261-265$.

Zar J. H. 1984. Biostatistical analysis. Second edition, Prentice-Hall, Inc., New Jersey: 1 - 718.

Received 19 November 1992, accepted 1 June 1993. 